\title{
Initial Development of a National Survey on Remote Learning in Early Childhood During COVID-19: Establishing Content Validity and Reporting Successes and Barriers
}

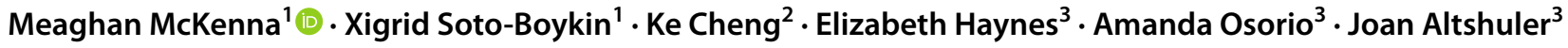

Accepted: 17 May 2021 / Published online: 1 June 2021

(c) The Author(s), under exclusive licence to Springer Nature B.V. 2021

\begin{abstract}
This article describes the development and administration of a survey to identify early childhood educators' successes and barriers when delivering remote instruction (e.g., online whole or small group instruction) during the COVID-19 pandemic to children 2-5 years old. The survey was developed using procedures outlined by the commonly accepted stages of an instrument development process. Content validity was established using four approaches: (a) identification of the purpose of the survey, (b) creation of a blueprint of items, (c) cognitive interviews, and (d) expert panel review. A total of 1,053 early childhood educators began the survey, with 808 (77\%) of the responses included because educators met the inclusion criteria of working in the United States and responding to at least one question related to remote instruction. The survey contained 37 closed-ended and six open-ended items covering eight domains: (a) demographic information; (b) preparation, guidelines, and materials for remote learning; (c) caregiver communication and engagement; (d) assessment; (e) instruction; (f) educators' levels of confidence before and after remote learning; (g) access to services (i.e., wraparound and/or special education); and (h) planning for the return to face-to-face instruction. Both quantitative (descriptive, t-test, regression, ANOVA, and Chi-square tests) and consensual qualitative research analyses were applied to summarize the survey results. Findings from this survey indicated that even with limited or no guidance from administrators, educators successfully adapted to remote instruction and their levels of confidence increased over time. Ongoing improvements need to be made to sustain regular communication with all families, to offer access to technology (i.e., devices and internet), to administer assessments or universal screeners, and to provide cohesive guidelines and expectations. Results from this study begin to shed light on early childhood educators' adaptation to remote instruction as a result of COVID-19.
\end{abstract}

Keywords Early childhood education $\cdot$ COVID-19 $\cdot$ Remote instruction $\cdot$ Survey

\section{Introduction}

In March of 2020, the COVID-19 pandemic arrived in the United States (U.S.) with unprecedented force and destructive, far-reaching health and economic effects (Center for Disease Control [CDC] 2020). To respond to the pandemic, brick and mortar schools serving nearly 57 million children

Meaghan McKenna

meaghanmckenna@ku.edu

1 Juniper Gardens Children's Project, University of Kansas, Kansas City, USA

2 Department of Educational and Psychological Studies, University of South Florida, Tampa, USA

3 Hillsborough County Public Schools, Tampa, USA in the U.S. were closed and unexpectedly transitioned to remote learning (Peele \& Riser-Kositsky 2020). Over 50\% of American children under the age of five were impacted by these school closures, based on the most recent enrollment data from the National Center for Education Statistics.

Remote learning (also known as distance learning) refers to educational opportunities provided outside of the traditional brick and mortar classroom (e.g., lessons sent to caregivers, virtual instruction). Despite the value of remote learning in reducing the proliferation of COVID-19, children, caregivers, and teachers have been tremendously affected by the U.S. education system's limited capacity to provide high-quality remote learning for sustained periods of time (Dorn et al. 2020). Presently, there is a scarcity of research focusing on how early childhood educators have been impacted by the COVID-19 pandemic or how they 
have adapted to providing remote instruction (e.g., Bassok, Michie, et al. 2020; Daro \& Gallagher 2020; Safi et al. 2020). Specifically, there is very limited knowledge regarding early childhood educators' successes and barriers when delivering remote learning. Understanding early childhood educators' success and barriers when delivering remote learning during COVID-19 is important as it can inform future policies and guidelines for providing young children with high quality, accessible remote instruction.

\section{An Overview of Early Childhood Education in the United States}

Efforts to provide young children with high-quality early childhood education stem from the acknowledgement that children's earliest years can set a trajectory for their future success (Fantuzzo et al. 2019). The provision of high-quality early learning is even more pressing for children who are Black, Latinx, and American Indian; children living in lowincome communities; and children with disabilities who have historically endured reduced access. Children who belong to two or more of these subgroups concurrently are at higher risk for persistent academic difficulties, making their access to education paramount (e.g., Blanchett et al. 2009). While children can attend Kindergarten through 12th grade through universal public education, early childhood education varies greatly in its format, funding, and workforce. In the U.S., early childhood education includes a wide range of programs (e.g., Head Start, In-Home Child Care) offered for part of the day, a full school day, or a full work day (Friedman-Krauss et al. 2020). Programs can be led by educational, social welfare, or commercial organizations, held in public elementary schools, centers, or homes, and funded by public or private sectors (Dowsett et al. 2008). Early childhood educators' educational backgrounds differ widely (e.g., Landry et al. 2009). Some early childhood educators teach without formal training, others need a child development associate's degree, and others need a minimum of a bachelor's degree (Education Development Center 2020).

Regardless of the setting in which early childhood educators work, they have an important role in preparing young children for success in school and life. One of the paramount responsibilities of early childhood educators is to plan and implement strengths-based, play-based learning opportunities addressing children's social emotional, physical, and cognitive development (American Federation of the State, County and Municipal Employees et al. 2020). The Professional Standards and Competencies for early childhood educators (National Association for the Education of Young Children 2019) encompass the knowledge, skills, dispositions, and practices required of all early childhood educators: (1) child development and learning; (2) family teacher partnerships and community connections; (3) child observation, documentation and assessment; (4) developmentally, culturally, and linguistically appropriate teaching practices; (5) knowledge, application, and integration of academic content in the early childhood curriculum; and (6) professionalism as an early childhood educator. Despite these great demands, many early childhood educators are paid minimum wage and receive limited professional development. Understanding early childhood educators' roles and responsibilities, as well as the nuances of various programs, is important when highlighting adaptation to remote learning during the COVID-19 pandemic.

\section{The Impact of COVID-19 on Early Childhood Educators}

Because high-quality education is crucial to young children's future success, it is important to acknowledge the role early childhood educators play in fostering children's development during the COVID-19 pandemic. Yet, there is presently limited knowledge on how early childhood educators have adapted to remote learning. To date, research has examined the extent to which COVID-19 has affected early childhood educators' engagement with children and families (Hanno et al. 2020), their emotional and financial well-being (Bassok et al. 2020a; Bassok et al. 2020b), and what is needed to provide children the essential service of early education (Daro \& Gallagher 2020; Safi et al. 2020; Szente 2020). Findings from these studies revealed that while most early childhood educators have been engaging families remotely, COVID-19 has reduced their wages (Bassok, Michie, et al. 2020), and amplified their emotional distress (Bassok, Markowitz, et al. 2020).

Previous surveys conducted in the states of Florida and Nevada indicate that early childhood educators have reported concerns with how to best engage children, what resources and tools to use during remote learning, and how to best communicate and build a classroom community online (Safi et al. 2020). They reported their top three professional development priorities included how to address children's social emotional development and challenging behaviors, how to implement COVID-19 health and safety protocols, and how to reduce their personal stress (Daro \& Gallagher 2020). Despite evidence that younger learners benefit from the structure of synchronous remote learning (Hodges et al. 2020), extant research on the impact of COVID-19 on early childhood educators and their students have highlighted significant challenges to remote instruction (e.g., Daro \& Gallagher 2020; Samuelsson, Wagner, \& Erikson, 2020). These challenges include states having varied policies and practices around early childhood remote learning due to a lack of uniform federal regulations (Samuelsson et al. 2020), 
early childhood educators' limited experience with remote learning (Jeffrey et al. 2020), and families' limited communication with teachers due to reduced access to technology, including internet and computer devices (Dias et al. 2020; Jeffrey et al. 2020). To further illustrate, Jeffrey et al. (2020) conducted a survey of Head Start educators in California who reported difficulty communicating with parents, maintaining motivation of parents and children, monitoring children's progress, and meeting children's social emotional needs while delivering remote learning. Like Dias and colleagues (2020), they also found barriers to remote learning included families' access to reliable devices, teachers' lack of experiences with virtual teaching, and reduced access to flexible teaching materials. These findings illustrate the importance of providing early childhood educators and caregivers with access to the tools and resources needed to effectively provide young children with remote learning opportunities (Szente 2020).

Szente (2020) concluded that successful remote learning in early childhood requires three types of access needs to be met. These types of access include: (1) formal access for early childhood educators and caregivers to technology; (2) actual access for where, when, and how early childhood educators and caregivers can access live virtual sessions and additional resources; and (3) functional access to early childhood educators', caregivers', and children's digital knowledge of how to use learning platforms. Samuelsson and colleagues (2020) illustrated an example of how a private early childhood center successfully implemented remote learning in ways that incorporated Szente's (2020) three recommendations for providing teachers, caregivers, and children access. For example, children ages 2-5 were offered three hours of real-time virtual instruction daily. The daily routine included music and movement, story time, gross motor activities, free-choice time, and teacher-directed literacy, science and mathematics activities to address the preschool's developmental and academic goals. Teachers emailed parents information regarding classroom activities and anticipated learning outcomes. Teachers created a YouTube channel where language arts, STEM, social science, and dramatic play activities were also made available to caregivers. Although Samuelsson's description of a model for successful remote learning in early childhood is beneficial, further research is needed to understand how early childhood educators across various settings and states adapted to remote learning.

Despite the growing number of studies focusing on the impact of the COVID-19 pandemic in early childhood educators' instruction, the extant body of literature on this topic is still limited. Most research has only focused on early childhood educators practicing in a few states and reported on how they adapted to remote learning using more general surveys and interviews about coping with the COVID-19 pandemic. Therefore, it is imperative to conduct more indepth research examining early childhood educators' successes and barriers when delivering remote learning to young children during the COVID-19 pandemic. Conducting a survey with a national representative sample of early childhood educators working across various states and work settings, and asking specific questions about approaches to remote instruction, will further elucidate how educators and policymakers can provide effective supports to meet the needs of young children affected by the pandemic.

\section{Purpose}

The highly contagious and potentially fatal COVID-19 virus disrupted the world's health, economic, and education systems, including those in the U.S. As instruction traditionally rendered in brick and mortar schools transitioned to remote learning, early childhood educators, caregivers, and children, had to quickly adapt to a new platform with little preparation. Since COVID-19 began interrupting the schooling of children in the U.S., researchers have been describing the impact of the pandemic on children's education and wellbeing. However, limited research has specifically focused on children who are between 2-5 years old. Extant research related to early childhood has focused primarily on early childhood educators' wages, emotional well-being, and interactions with children and parents during the pandemic. However, these studies have significant limitations. First, the bulk have not been peer-reviewed. Second, they only include data on specific regions of the U.S. Third, very few focus on how early childhood educators adapted to remote learning as a result of COVID-19. Because early childhood is highly varied in its format, funding, and workforce, and remote learning is novel for early childhood educators serving younger children, it is imperative to investigate early childhood educators' adaptation to remote learning.

The purpose of the present study is to report the initial validation and findings of a national survey of early childhood educators who delivered remote learning to children ages 2-5 years of age when the COVID-19 pandemic began. These data are vital for increasing awareness and providing guidelines that administrators, early childhood educators, and policymakers, can disseminate to promote young children's future academic success. The following aims were addressed:

\section{Aim 1}

To describe how early childhood educators adapted to remote learning during COVID-19 in terms of preparation, guidelines, and materials for remote learning; caregiver 
communication and engagement; assessment; instruction; and levels of confidence.

\section{Aim 2}

To use early childhood educator, child, and caregiver demographic data to conduct preliminary analyses to explore the equity of remote learning in terms of program type and socioeconomic subgroups.

\section{Aim 3}

To identify successes and barriers associated with remote learning, determine strategies used to differentiate instruction for children at-risk and/or children with special needs, and describe early childhood educators' plans for returning to remote, hybrid, or face-to-face models of instruction.

\section{Methods}

\section{Survey Development}

The Early Childhood Remote Learning Survey was developed using procedures outlined by the commonly accepted stages of an instrument development process (McCoach et al. 2013). Content validity procedures allowed for the adequate coverage of items on the survey in relation to remote/distance learning provided by early childhood educators during COVID-19 school closures construct (Messick 1975). The process used to generate and review the items played a critical role in enhancing the content validity of the survey. Content validity was assessed using four approaches: (a) identification of the purpose of the survey and the target group (i.e., early childhood educators teaching children 2-5 years of age), (b) creation of a blueprint of items with members of a school district leadership team, (c) cognitive interviews with five early childhood educators working across the U.S., and (d) expert panel review by six early childhood researchers.

\section{Identification of the Purpose of the Survey}

Existing surveys were reviewed (e.g., Bassok, Markowitz, et al. 2020; Bassok, Michie et al. 2020; Hanno et al. 2020). It was evident that these surveys could not adequately represent the construct of interest because they did not contain questions specific to instruction. The first author, who was working for a school district at the onset of COVID19 , partnered with members of the early childhood team (authors four, five, and six) to develop remote learning resources for 3-5 year old children in Head Start, Special Education, Voluntary PreKindergarten, and Blended
Voluntary PreKindergarten and Special Education classrooms when COVID-19 began. These authors generated the initial item pool along with the second author who was collaborating with a private preschool.

\section{Creation of a Blueprint of Survey Items}

A test blueprint of initial items was created. It contained 26 closed-ended and 3 open-ended items. The items covered six domains: (a) educator and child demographic information, (b) caregiver communication, (c) assessment, (d) instruction, (e) early childhood educators' levels of confidence before and after remote learning, and (f) access to wraparound services. The term "wraparound services" is representative of a philosophy of care intended to effectively integrate education with social services, health, and mental health resources to achieve positive outcomes.

\section{Cognitive Interviews}

Cognitive interviewing was used during survey item development to critically evaluate if the information was effectively conveyed. Cognitive interviewing is conducted to evaluate the manner in which the targeted audience understands, processes, and responds to survey items is studied (Willis 2004). During cognitive interviewing, individuals talk aloud to express their thoughts as they complete the survey.This type of interviewing allows for opportunities to rephrase items for clarity. Cognitive interviews were held via phone with five early childhood educators from across the U.S. who provided remote learning in March 2020 when school closures began. All of the early childhood educators who participated were teaching children 2-5 years of age, in Head Start, private childcare, special education, or inclusive preschool programs. The interviews were conducted using both think-aloud and verbal prompting procedures (Willis 1999). A copy of the survey was emailed to each of the early childhood educators prior to the interview. After the early childhood educators read each item, they shared their interpretation about what it meant and provided feedback. Any unclear items were discussed and revised. The early childhood educators answered each of the items based on their experiences and felt all items were relevant to remote learning. They made suggestions for adding 15 closed-ended items, 3 open-ended items, and an opportunity for early childhood educators to provide any comments related to areas that were not addressed on the survey. Further revisions to the survey were made following completion of the cognitive interviews before beginning the expert panel review. 


\section{Expert Panel Review}

Six researchers who conduct studies with children birth through five years old completed an expert panel review. Prior to working full time in higher education, panelists served in various roles in interdisciplinary early intervention and early learning programs for young children, their families, and the personnel who support them. A copy of the survey was emailed to the experts asking them to provide feedback on the relevance and clarity of items. Experts recommended revising 10 items. There were two occurrences where experts suggested combining two-closed ended items. The revised survey found in Supplemental Materials was entered into Qualtrics to prepare for dissemination to early childhood educators across the U.S.

The final survey consisted of three sections. The eligibility section contained a question to determine if the early childhood educators provided remote learning to children $2-5$ years of age as a result of COVID-19. The survey item section contained 37 closed-ended and six open-ended items used to describe remote learning opportunities provided to children and their caregivers. The additional comments section allowed early childhood educators to share any information they determined was not included within their responses. Prior to broadly distributing the Qualtrics link to early childhood educators, the first author used the preview feature to make sure all items were functioning appropriately.

\section{Survey Dissemination}

In July of 2020, the survey was shared using convenience sampling. An infographic and paragraph explaining the survey invited early childhood educators who provided remote learning opportunities to children ages $2-5$ beginning in March 2020 to participate. This was posted on social media (i.e., Twitter, Facebook groups, and Instagram accounts frequently accessed by early childhood educators [e.g., Head Start, NAEYC, and DEC Community Pages, State Preschool Pages]). One follow-up reminder was given on the Facebook pages that approved the initial post a week later. All survey responses were collected during a 20 day period.

\section{Participants}

A total of 1,053 early childhood educators began to complete the survey after agreeing to the consent form approved by the Institutional Review Board. We ensured protection of participants by using de-identifiable participant numbers and storing the survey data in an encrypted online database, where only authorized research personnel have access. Participants had the opportunity to provide an email address if they wanted to receive a summary of the survey results.
They were made aware that it is possible, with internet communications, that through intent or accident someone other than the intended recipient may see their response. These were conditions that participants consented to before beginning the survey. Two hundred and eleven responses were omitted because the participant completed less than $27 \%$ of the survey and did not answer any of the questions that corresponded to providing remote instruction. Thirty four responses were omitted because the early childhood educators taught outside of the U.S. The 808 early childhood educators whose data were analyzed practiced in all 50 states. Their total years of work experience ranged from six months to 50 years and 576 held a state teaching certificate. Early childhood educators worked for a variety of programs; 196 Head Start, 187 Inclusion, 142 Special Education (self-contained), 78 voluntary prekindergarten, 174 private preschool, and 31 worked in other settings. Early childhood educators reported the socioeconomic status of most families in their class; 443 reported low, 328 reported mid, and 34 reported high.

\section{Data Analysis}

Item nonresponse can never be completely prevented when conducting survey research because participants choose the items they complete and items on this survey may not have been applicable to all early childhood educators. The partial nonresponse data were included so that information on the questions answered was not lost (DeLeeuw et al. 2003). The total number of early childhood educators who answered each question is included in the results. The available data from the closed-ended questions were quantitatively analyzed through descriptive statistics using frequency and percentage to assess how early childhood educators adapted to remote learning. Independent sample t-test, ANOVA, regression, and Chi-square tests were used to investigate the relationship between item responses and demographic characteristics. The available data from the open-ended questions were analyzed using consensual qualitative research (Hill et al. 1997) to identify themes.

\section{Results}

A total of 26 closed-ended questions were analyzed descriptively to address the first aim related to how early childhood educators' adapted to remote instruction. The questions provided information about preparation, guidelines, and materials for remote learning; caregiver communication and engagement; assessment; instruction; and early childhood educators' levels of confidence. The frequency of the responses were analyzed and a t-test was conducted 
to compare levels of confidence at the beginning of remote learning in March 2020 to the end of the school year in May or June 2020.

\section{Preparation, Guidelines, and Materials for Remote Learning}

Only 446 of 805 early childhood educators were given time to prepare for remote instruction. Preparation ranged from a few hours to one month. Most early childhood educators, $131(31 \%)$ of 424 early childhood educators had five days to prepare. No guidelines/expectations for remote learning were provided by administration to 198 (25\%) of 791 early childhood educators. The majority of the remaining early childhood educators selected that only one $(196 ; 33 \%)$ or two $(166 ; 28 \%)$ guidelines/expectations were provided. Most, 382 (64\%) early childhood educators, received expectations for daily activities. A scope and sequence for instruction was the option selected least often by $108(18 \%)$ early childhood educators. Of the 786 respondents, 391 (46\%) indicated that a device (e.g., computer, tablet) was provided to caregivers who requested one. In total, 391 (50\%) of 781 early childhood educators said caregivers received assistance with obtaining internet access, while 771 early childhood educators shared how they obtained lessons, materials, and resources to use during remote learning. The majority, 673 (87\%), of the early childhood educators indicated that they had developed everything themselves. The option selected least often by 32 (4\%) early childhood educators was that a coach made lessons, materials, and resources. Of the 671 early childhood educators who reported type(s) of training received during remote learning, 178 (27\%) indicated they had no training opportunities available and 25 (4\%) of these early childhood educators chose not to participate in training. The majority, 353 (53\%), attended training related to the successful use of technology during remote learning. Trainings least frequently attended by $23 \%$ of early childhood educators were related to engaging caregivers and designing lessons for remote learning.

\section{Caregiver Communication and Engagement}

A total of 793 early childhood educators shared how they communicated with caregivers during remote learning. Only three (less than 1\%) reported that they did not communicate with caregivers. The majority, 737 (93\%) early childhood educators used two or more modes of communication. All modes were frequently used; emails were selected most often by 688 (87\%) early childhood educators and texts were selected least often by 549 (69\%) early childhood educators. Six hundred and seventeen early childhood educators reported that languages other than English were spoken in the homes of children in their classroom. The largest percentage, 534 (87\%) early childhood educators indicated that Spanish was spoken. Early childhood educators listed a total of 84 different languages. Six hundred and eighty two early childhood educators shared how they communicated with caregivers who spoke a language other than English. Thirteen (2\%) indicated that they did not communicate with caregivers. The item selected most frequently by 462 (68\%) early childhood educators was that parents spoke some English and the item selected the least often by $119(17 \%)$ early childhood educators was that the classroom paraprofessional or assistant served as a translator. Six hundred ninety-five early childhood educators indicated what caregivers found helpful about the lesson plans, materials, and resources provided during remote learning. Ten early childhood educators (1\%) reported that the caregivers of children in their classroom did not participate or provide feedback. The majority, 499 (72\%) early childhood educators, reported that caregivers found three or more things helpful. Play-based learning activities for home was selected most often by 541 (78\%) early childhood educators and assessment/progress monitoring was selected least often by 48 (7\%) early childhood educators. Six hundred and seventy-five early childhood educators shared how their program, school, or district engaged families during remote learning. Four early childhood educators (less than 1\%) reported that they were the only one reaching out to engage families during remote learning. Programs, schools, and districts that communicated with families also used a variety of modes, with 588 (88\%) of responding early childhood educators indicating that two or more modes of communication were used. Most programs 561 (84\%) engaged families via email, while automated messaging was selected least frequently by 313 (47\%).

\section{Assessment}

Only 62 (8\%) of 788 early childhood educators reported administering an assessment or universal screener during remote learning. Forty-three (73\%) of 59 early childhood educators assessed communication/language and 42 (71\%) assessed math. Science was assessed least often by $22(37 \%)$ early childhood educators. Sixty early childhood educators shared the assessment they used. The majority, 26 (43\%) early childhood educators used an assessment they developed and only two (3\%) early childhood educators reported using the Star Early Literacy Assessment (Renaissance Learning, 2020). Sixty-one of the early childhood educators shared how the assessments were administered. The majority, 47 (77\%) early childhood educators administered the assessment via a virtual platform and the option least often selected by five (8\%) early childhood educators was that a parent administered via virtual platform with them observing. Forty-one (66\%) early childhood educators said that fidelity was monitored through the use of a checklist and/ 
or observation during the assessment. There was variability in the responses that 682 early childhood educators gave when asked how often caregivers provided updates because frequency of communication differed with each family. The early childhood educators most frequently selected that they were able to connect with families once per week 160 (23\%) or a few times per week 161 (24\%). The option selected the least by 28 (4\%) early childhood educators was that they never communicated with families. Six hundred forty-one early childhood educators monitored and assessed children's response to remote learning. The majority, 555 (87\%) early childhood educators used pictures sent by the families. Data from computerized assessments (e.g., IXL, Waterford) was used least often by 47 (7\%) early childhood educators.

\section{Instruction}

Virtual whole group sessions were held by 485 early childhood educators with most, 196 (40\%), facilitating sessions once per week. Virtual small group sessions were held by 230 early childhood educators, with the majority, 105 (46\%), providing sessions a few times per week. Virtual individual sessions were held by 267 early childhood educators, with most, 132 (49\%), providing one-on-one instruction once per week. An email with activities was sent by 498 early childhood educators, with the bulk, 201 (40\%), sending an email once per week. Lessons were posted to an online learning platform (e.g., Google classroom, Canvas) by 519 early childhood educators, with the majority, 297 (57\%), doing this daily. Recorded video lessons were shared by 497 early childhood educators, with most, 191 (39\%), sharing them every day. Seven hundred and forty-eight early childhood educators selected the domain(s) addressed by the lessons, resources, and/or materials used during remote learning. The majority, 308 (41\%) reported addressing seven domains. Communication/language was addressed most frequently by 694 (93\%) early childhood educators and writing was addressed least often by 521 (70\%). Of the 753 responding early childhood educators, 603 (80\%) recommended online websites in addition to the lessons, materials, and/or resources provided to caregivers. Over 100 websites were used, with ABC Mouse reported most frequently. by 195 (40\%) of the 486 early childhood educators who shared specific websites. Seven hundred and twenty-two early childhood educators shared how often they met or communicated with other teachers or their team members for planning. Early childhood educators most frequently reported meeting or communicating once per week $249(34 \%)$ or a few times per week $223(30 \%)$ while $122(17 \%)$ reported meeting or communicating daily and 104 (14\%) reported meeting never. There were 567 (82\%) of 693 early childhood educators who worked with a paraprofessional or classroom assistant. Five hundred twenty early childhood educators shared how the paraprofessional assisted them during remote learning. Eighty-seven (17\%) early childhood educators noted that the paraprofessional did not support them when remote learning began. The majority of early childhood educators, 212 (49\%), who received support during remote learning were assisted with one activity. Most early childhood educators, 279 (64\%), received support with preparing materials to send home or post for caregivers and children, whereas assistance with assessment was selected least frequently by only $15(3 \%)$.

\section{Early Childhood Educators' Confidence}

In terms of their level of confidence $(1=$ Not at all confident, $2=$ Somewhat confident, $3=$ Confident, and $4=$ Very Confident), 806 early childhood educators reported their confidence at the beginning of remote learning (March 2020) and 655 early childhood educators reported their confidence at the end of the 2019-2020 school year (May/June 2020). We found a statistically significant difference in mean level of confidence at the beginning of remote learning (1.64) when compared to the mean level of confidence at the end of remote learning $(\mathrm{p}=0.00, \mathrm{df}=654, t=81.52)$. The confidence at the end of remote learning was 0.85 points $(95 \%$ $\mathrm{CI}=2.43-2.55$ ) higher than at the beginning.

\section{Inferential Statistical Analysis}

Responses to six closed-ended questions were analyzed using inferential statistics to address the second aim to begin exploring equity of remote learning in early childhood in terms of program type and socioeconomic subgroups. Considering the nature of the dataset, logistic regression analyses were applied to determine if differences existed among the various types of early childhood programs on providing devices, assisting caregivers with accessing the internet, and allocating day(s) to plan for remote learning. Differences among the socioeconomic subgroups regarding the number of wraparound services received, access to devices, and assistance with the internet were determined by applying ANOVA and Chi-square tests.

Table 1 contains findings from logistic regression analyses between different programs and devices provided, assistance with internet access, and days to plan for remote learning. Head Start and private preschool programs were significant when compared to the other programs for providing devices and assistance with the internet. Private preschool and voluntary preschool programs were significant when compared to the other programs for offering time to plan.

The average number of wraparound services offered to families in the low socioeconomic group was 2.56 , which 
Table 1 Logistic regression analyses between programs

\begin{tabular}{lllll}
\hline Programs & Device provided & $\begin{array}{l}\text { Assistance with } \\
\text { internet access }\end{array}$ & $\begin{array}{l}\text { Days to plan for } \\
\text { remote learning }\end{array}$ \\
\hline Head Start & B & $1.50^{*}$ & $1.35^{*}$ & 0.67 \\
& S.E & 0.41 & 0.44 & 0.42 \\
Inclusion & B & -0.04 & 0.13 & 0.38 \\
& S.E & 0.41 & 0.46 & 0.42 \\
Private & B & $1.89^{*}$ & $2.68^{*}$ & $1.21^{*}$ \\
Preschool & S.E & 0.43 & 0.47 & 0.43 \\
Special & B & -0.60 & 0.02 & 0.38 \\
Education & S.E & 0.43 & 0.46 & 0.43 \\
Voluntary & B & 0.80 & 0.84 & $1.00^{*}$ \\
Prekindergarten & S.E & 0.44 & 0.47 & 0.46 \\
\hline
\end{tabular}

Note. For Device Provided: $\mathrm{N}=786$ (97.3\%) Missing $=22(2.7 \%)$ Intercept $=-3.01$; For Assistance with Internet Access $\mathrm{N}=781$ (96.7\%) Missing $=27$ (3.3\%) Intercept $=-4.05$; For Days to Plan to Remote Learning: $\mathrm{N}=805(99.6 \%)$ Missing $=3(0.4 \%)$. Intercept $=-2.73$; Degrees of Freedom for all the programs is 1; *means p-value $<.05$
Table 2 ANOVA for socioeconomic status and number of wraparound services provided

\begin{tabular}{lrlrll}
\hline & $\begin{array}{l}\text { Sum of } \\
\text { squares }\end{array}$ & $d f$ & $\begin{array}{l}\text { Mean } \\
\text { square }\end{array}$ & F & p-value \\
\hline Between Groups & 178.88 & 2 & 89.44 & 45.42 & .000 \\
Within Groups & 1504.28 & 764 & 1.97 & & \\
Total & 1683.15 & 766 & & & \\
\hline
\end{tabular}

Note. $d f=$ Degrees of Freedom

was higher than the mid socioeconomic group average of 1.69 , and the high socioeconomic group average of 1.03 . Based on the post hoc Tukey HSD tests, the high socioeconomic group was statistically significantly different from the mid socioeconomic group and low socioeconomic group and the mid socioeconomic group was statistically significantly different from the low socioeconomic group. Table 2 contains ANOVA results. Tables containing the Pearson Chi-Square tests conducted to assess access of each socioeconomic subgroup to devices and internet are available in Supplemental Materials. Results for each subgroup's access to devices $\chi^{2}(2, \mathrm{~N}=783)=7.54, \mathrm{p}=0.023$ and internet access $\chi^{2}(2, \mathrm{~N}=778)=8.62, \mathrm{p}=0.013$ were statistically significant. The effect size for the $\chi^{2}$ test is $\mathrm{Phi}=0.098$ which is considered small.

\section{Qualitative Analysis}

The six open-ended questions were analyzed qualitatively to address the third aim of identifying successes and barriers associated with remote learning, determining strategies used to differentiate instruction for children at-risk and/or children with special needs, and describing early childhood educators' plans for returning to remote, hybrid, or face-toface models of instruction. The same open-ended questions were presented to all survey participants to allow for consistent collection of data. Two judges (the first and second author) analyzed the data to foster multiple perspectives and meetings were held to arrive at a consensus about the meaning of the data. Two auditors (the fourth author and an elementary teacher with 7 years of experience) checked the work of the primary team of judges and agreed with all findings.

\section{Successes}

Four hundred and twenty (52\%) early childhood educators shared successes with remote learning or what they would continue when face-to-face learning resumes. Early childhood educators successfully engaged caregivers through constant communication (e.g., emails, apps, video conferencing), flexible scheduling, and easy to implement lessons aligned with daily routines. One early childhood educator stated, "A lot of practical activities to learn new concepts. Definitely changing my classroom routine to do the same activities." Early childhood educators described how quickly children adapted to technology. Early childhood educators recommended websites (e.g., BOOM cards, IXL) that collected data allowing for monitoring of children's progress and instruction targeting individual needs. Based on these successes, many early childhood educators reported that they will continue collaborating with caregivers even when faceto-face instruction resumes. One early childhood educator said, "We learned to utilize SeeSaw during remote learning and I will continue to use it. I also used surveys to determine parent needs and I will continue this." 


\section{Barriers}

Four hundred and sixty four (57\%) early childhood educators reported barriers during remote learning. Early childhood educators' greatest barriers included limited accessibility to technology for both themselves and caregivers; lack of administrators' training and guidelines; and difficulty scheduling lessons due to caregivers' time constraints. An ECE stated, "Some students had slow internet which caused them to miss out on Zoom meetings." Another said, "Lack of technology capabilities with families and their schedules drastically changed overnight." Early childhood educators reported it was arduous to sustain caregivers' and children's engagement over time and communicate with families who spoke a language other than English. Some early childhood educators reported it was challenging to follow the Individual Education Plan (IEP) of children with special needs and to monitor their progress. Finally, early childhood educators shared the uncertainty resulted in mental health difficulties for both themselves and caregivers. Others expressed frustration towards poor treatment of early childhood educators and children and said the transition to remote learning solidified their decision to leave early childhood education.

\section{Differentiating Instruction for Children at-Risk and/ or Children with Special Needs}

Three hundred and ninety two (49\%) early childhood educators noted strategies used to engage and differentiate instruction for children at-risk or with special needs. Early childhood educators (27\%) reported that interactive activities (e.g., scavenger hunts, read alouds, fingerplays) that were fun, animated, and included manipulatives (e.g., core boards, visual schedules) were successful. Early childhood educators (6\%) collaborated with service providers (e.g. speech-language pathologists) to add accommodations and/or specific activities to weekly plans or to coordinate schedules. Thirtyseven percent of educators provided different options for activities and/or levels of prompting to assist families with completing activities and coaching on how to address Individualized Family Service Plan (IFSP) or IEP goals. Early childhood educators emphasized the importance of keeping lessons short, providing options (e.g., activities in binders/ folders sent home, websites), and reinforcing (e.g., child's favorite song). A few early childhood educators shared that it was challenging to meet everyone's needs or that they provided activities even though they were unpaid during this time.

\section{Establishing Relationships with Caregivers}

Four hundred and sixty three (57\%) early childhood educators shared how they would establish relationships with caregivers and children if remote learning continued during the 2020-2021 school year. Early childhood educators expressed they plan to maintain communication with families through a variety of platforms; adapt to caregivers' schedules; set clear expectations and guidelines; create engaging activities to welcome the children; establish routines/lessons that can be easily implemented at home; distribute lesson materials to homes; and provide caregivers with resources and ongoing assistance to help reduce their anxiety related to instruction of their children. For example, one early childhood educator listed what she planned to do: "I would love to be able to meet physically with each family (with masks/social distancing guidelines in place) if my district allows. Absent this opportunity we will have several online orientations with small groups of families and offer 1:1 meetings digitally as well. During the first several weeks of school we will be trying to do assessments with each student one at a time by appointment online-this will also provide an opportunity to get to know each kiddo more personally and establish a rapport." A group of early childhood educators indicated that they already had relationships with caregivers and children as they would work with the same class again. Others were waiting for guidance from their administration or felt unsure about how to establish relationships if remote learning continued.

\section{Changes Based on CDC Guidelines}

Four hundred and eighty three (60\%) early childhood educators shared the changes they were making to comply with CDC Guidelines upon returning to face to face instruction. Some said screenings (i.e., temperature checks) would occur upon arriving to the building and before nap time, Personal Protective Equipment (PPE; e.g., masks, shields) would be worn, and classrooms would be arranged for social distancing (e.g., spaced out tables, plexiglass, individualized resources and materials). Early childhood educators reported that limited movement outside of the classroom would occur. Schedules for visiting the playground and social stories explaining changes would be developed. Some early childhood educators said class sizes would be reduced or they would deliver a hybrid model of instruction where children came to school only a few days each week.

\section{Enhancing Instruction upon Return to School}

Four hundred and fifteen (51\%) early childhood educators answered the question about how they will enhance instruction to address children's gaps in knowledge once face-toface learning resumes. Several early childhood educators expressed they will need to learn new procedures for providing face-to-face instruction during the pandemic and that they will need administrators' guidance. They reported 
they will assess children to drive their instruction and adapt lessons to foster children's engagement. One early childhood educator stated, "Building resilience and relationships monitoring and assessing development upon return, developing early help plans for children identified with gaps." Many early childhood educators expressed they will focus on promoting children's socio-emotional well-being using trauma-informed care and re-establish classroom routines and teacher-child relationships. Other early childhood educators noted they will collaborate with paraprofessionals to maximize learning opportunities, and that they will benefit from professional development focusing on the use of technology to facilitate instruction. Early childhood educators also reported they will need additional funding to purchase instructional materials designed to enhance learning to accommodate children's hiatus from face-to-face instruction.

\section{Discussion}

This paper describes early childhood educators' practices, successes, and barriers when delivering remote instruction to two through five yearold children due to COVID-19-related school closures beginning in March of 2020. The Early Childhood Remote Learning Survey was designed to gather preliminary data to better inform practice as a result of the ever-changing educational landscape during the COVID-19 pandemic. We addressed our three aims using descriptive statistics, inferential statistics, and consensual qualitative research analyses.

The first aim was to describe how early childhood educators have adapted to remote learning in terms of their instructional format, communication with caregivers, administration of assessment, and their levels of confidence. The results revealed that although most early childhood educators reported having little or no administrative support, they adapted to remote instruction and used various formats (e.g., live lessons, videos, home packets) with activities that addressed all domains in early learning and developmental state standards (e.g., social emotional learning, mathematical thinking, literacy, scientific inquiry) and could easily be integrated into home routines making instruction accessible to families. Most early childhood educators reported that caregivers varied in their participation in virtual instruction. While early childhood educators reported many families checked in multiple times throughout the week, there were some families who required ongoing outreach through different modalities (e.g., phone calls, texting). This finding is supported by previous research examining parents' financial and emotional stress during COVID-19 (Russell et al. 2020). As parents have adapted to working remotely while taking care of their children, it is plausible that this impacted their availability to communicate with early childhood educators during remote instruction (Greszler et al. 2020). We also found that early childhood educators used primarily informal assessments (e.g., pictures) to monitor learning, but they did not use formal or standardized assessments. Given that children are missing face-to-face instruction, it is vital to examine their progress using valid and reliable measures. Assessment developers are publishing guidance and making modifications to ensure assessments can be delivered remotely (e.g., Individual Growth and Development Indicators, Preschool Early Literacy Indicators). The statistically significant difference in early childhood educators' levels of confidence at the beginning of remote learning when compared to the end of the school year, are in line with prior research indicating teachers' self-reflection contributes to increased knowledge and instructional quality (Escamilla \& Meier 2018). This finding is also consistent with increases in educator confidence as they gain more teaching and computer experience and receive more training (Nikolopoulou \& Gialamas, 2015). After remote instruction began, educators had opportunities for collaboration with their school team or through early childhood groups on social media. Resources other early childhood educators found to be successful when delivering remote instruction also began to become available.

The second aim was to use demographic data to conduct preliminary analyses to explore whether all children, caregivers, and early childhood educators received equitable access to remote learning. Differences existed among the types of programs in access to technology (i.e., devices, internet) provided to families. This was consistent with Blackwell et al. (2013) who found that devices (e.g., computers, tablets) in classrooms varied by program. Access to the internet may have been impacted depending on the providers who partnered with programs because many only offered free services for a limited time (Armstrong 2020). Additionally, location may have been a factor since $31 \%$ of rural households in the U.S. lack internet access (Federal Communication Commission 2018). The different program funding sources (Friedman-Krauss et al. 2020) may have also affected the ability to purchase devices or hotspots. Funding or calendars may have influenced time allocated to pay early childhood educators to plan. Many early childhood educators noted that they were on spring break when they found out they would not be returning back to work or that any remote instruction they provided during program closures was unpaid. Families from the lowest socioeconomic subgroup received the most wraparound services and the most assistance with access to technology; however, the small effect size indicates that ongoing improvements are needed to ensure equity. While COVID-19 doesn't discriminate on the basis of socioeconomic status, the impact of the pandemic appears more harmful to subgroups of individuals who are ethnically/racially minoritized (Ambrose 2020). 
The third aim was to identify successes and barriers associated with remote learning during the COVID19 pandemic, determine strategies used to differentiate instruction for children at risk and/or children with special needs, and describe early childhood educators' plans for returning to remote, hybrid, or face-to-face models of instruction. There were overlapping themes that included successful communication with caregivers, access to reliable technology, use of activities that can be integrated into daily home routines, clear guidelines and expectations (e.g., scheduling, progress monitoring) provided by administrators for all children especially those with IFSPs and IEPs, and access to training opportunities for ongoing updates and to advance ECE knowledge. As a result of all of the attention placed on early childhood, having a well-equipped administration is an important consideration. Goffin (2013) described early childhood as experiencing a dearth in leadership capacity. To address this risk of long-term academic difficulty resulting from the pandemic, it is recommended that administrators in education programs: address the barriers that children vulnerable to educational disparities might face; provide early childhood educators and caregivers with instructional guides adapted to the challenges and constraints of remote learning; and maintain communication among school leaders, caregivers, and early childhood educators (Reich 2020). Early childhood educators' responses while living and working in a pandemic exemplified resilience, self-reflection, and ongoing on-the-job-learning as they adapted to remote instruction. Early childhood educators were persisting amidst daily challenges (Beltman et al 2011). They were learning from their experiences and finding motivation in creating solutions to problems that arose (Hunzicker 2011) by partnering with caregivers. Early childhood educators acknowledged the continuous improvements they made, yet feelings of isolation existed as a result of the limited resources available and recognition received for their efforts. Oftentimes, guidelines or online materials accessible through work settings were only applicable to older students (i.e., preschoolers preparing for kindergarten entry, children in elementary grade levels). Some early childhood educators noted that if remote instruction continued without the appropriate training, resources, and/or support from administration they would leave their position. Early childhood educators attended training from providers outside of their school and looked online for suggestions when what was made available was nonexistent or poor in quality. These concerns are consistent with conditions associated with the instability of the early childhood workforce (e.g., Kwon et al. 2020) and the need for efforts to support early childhood educators' social emotional capacity (Buettner et al. 2016).

\section{Limitations}

Although the present study had significant strengths, such as inclusion of a national sample of early childhood educators, and comprehensive analyses of the data using various methods, it also contains limitations worth noting. Convenience sampling was used and therefore it is unclear if the answers provided by those who completed the survey are representative of responses of the population of early childhood educators. A rate of return could not be calculated. The missing data that resulted because participants selected the questions they answered may have biased these results as well. While content validity was established prior to disseminating the survey, the initial administration of the survey was also when pilot testing occurred so data obtained from the survey could be used as early as possible to inform the field during the pandemic. The survey was developed to obtain descriptive information because this questionnaire wasn't intended to measure constructs; thus, there are no psychometric properties associated with this survey.

\section{Future Research}

Disseminating information to early childhood educators about how they can provide young children and caregivers with meaningful learning opportunities outside of the traditional brick and mortar setting is needed. Information learned from this survey could be used to develop interview protocols for further exploration. Since early childhood educators who participated in this survey may have continued with remote learning during the summer or throughout the 2020-2021 school year questions related to changes in their instructional delivery and updated guidance provided by administrators can be asked. Additionally, studies addressing sustaining and maintaining participation from families over time, effective procedures for administering remote assessments to measure child development, and identification of the resources, materials, and approaches to instruction that are perceived useful by caregivers and lead to learning gains are needed.

\section{Conclusion}

The Early Childhood Remote Learning Survey captured information on how early childhood educators adapted to remote instruction during March-May/June of 2020. These preliminary findings allow us to begin recognizing elements needed for successful delivery of remote instruction. Often research on early education has prioritized evaluating 
particular programs (e.g., Head Start, private preschool) instead of determining the common practices that all early childhood educators can implement that contribute to significant advancements in children's academic and behavioral skills (Duncan \& Magnuson 2013). Early childhood educators from all different types of programs who took this survey have contributed to these findings. Moving forward collaboration among both administrators and early childhood educators from all programs, especially during crises such as the COVID-19, would allow for problem-solving that may potentially lead to advancements for all children and impact school readiness long-term. These data may prompt dissemination of resources to assist all early childhood educators, regardless of programs, as they work on providing the best remote learning experiences to children and families. After all, as we have learned from the challenges associated with the COVID-19 pandemic, we are better and stronger together.

Acknowledgements Thank you so much to all of the early childhood experts and educators who contributed to the development of this survey and chose to participate in this study. The findings have informed efforts to optimize young children's success when participating in remote instruction during the time of COVID-19. We are extremely grateful!

Funding This work was supported by Grant No. R324B180004 from the Institute of Education Sciences, U.S. Department of Education, awarded to the University of Kansas. The opinions expressed are those of the authors and do not represent views of the Institute or the U.S. Department of Education.

\section{Declarations}

Conflict of interest There are no relevant conflicts of interest.

Supplementary Information The online version contains supplementary material available at https://doi.org/10.1007/s10643-021-01216-y.

\section{References}

Ambrose, A. J. H. (2020). Inequities during COVID-19. Pediatrics, 146(2), 1-3. https://doi.org/10.1542/peds.2020-1501

American Federation of State, County and Municipal Employees, American Federation of Teachers, Associate Degree Early Childhood Teacher Educators, Child Care Aware of America, Council for Professional Recognition, Division for Early Childhood of the Council for Exceptional Children... \& Zero to Three (2020). Unifying Framework for the Early Childhood Education Profession. Washington, DC: NAEYC. Retrieved from http://powertotheprofe ssion.org/unifying-framework

Armstrong, R.L. (2020). Your guide to internet service during new coronavirus (COVID-19) outbreak. Retrieved from https://www. highspeedinternet.com/resources

Bassok, D., Markowitz, A. J., Smith, A., \& Kiscaden, S. (2020a). Child care leaders' experiences with COVID-19: First findings from the study of early education in Louisiana. Retreived from https://
curry.virginia.edu/sites/default/files/uploads/epw/COVID\%20Lea der\%20Rept\%20July\%20\%20Update.pdf

Bassok, D., Michie, M., Cubides-Mateus, D. M., Doromal, J. B., \& Kiscaden, S. (2020b). The divergent experiences of early educators in schools and child care centers during COVID-19: Findings from Virginia. Panel presented at the 42nd Annual Association of Public Policy Analysis and Management. Retreived from https:// files.elfsight.com/storage/022b8cb9-839c-4bc2-992e-cefccb8e87 7e/710c4e38-4f63-41d0-b6d8-a93d766a094c.pdf

Becker, S. P., Breaux, R., Cusick, C. N., Dvorsky, M. R., Marsh, N. P., Sciberras, E., \& Langberg, J. M. (2020). Remote learning during COVID-19: examining school practices, service continuation, and difficulties for adolescents with and without attention-deficit/ hyperactivity disorder. Journal of Adolescent Health, 67(6), 769777. https://doi.org/10.1016/j.jadohealth.2020.09.002

Beltman, S., Mansfield, C., \& Price, A. (2011). Thriving not just surviving: a review of research on teacher resilience. Educational Research Review, 6(3), 185-207.

Blackwell, C. K., Lauricella, A. R., Wartella, E., Robb, M., \& Schomburg, R. (2013). Adoption and use of technology in early education: the interplay of extrinsic barriers and teacher attitudes. Computers \& Education, 69, 310-319. https://doi.org/10.1016/j. compedu.2013.07.024

Blanchett, W. J., Klingner, J. K., \& Harry, B. (2009). The intersection of race, culture, language, and disability: implications for urban education. Urban Education, 44(4), 389-409.

Blundell, R., Costa Dias, M., Joyce, R., \& Xu, X. (2020). COVID-19 and Inequalities. Fiscal Studies, 41(2), 291-319.

Buettner, C. K., Jeon, L., Hur, E., \& Garcia, R. E. (2016). Teachers' social-emotional capacity: factors associated with teachers' responsiveness and professional commitment. Early Education and Development, 27(7), 1018-1039. https://doi.org/10.1080/ 10409289.2016 .1168227

Center for Disease Control (2020). COVID-19. Retrieved from Coronavirus Disease 2019 (COVID-19) CDC

Daro, A., \& Gallagher, K. (2020). The Nebraska COVID-19 early care and education provider survey II: Experiences, economic impact, and ongoing needs. Retrieved from https://buffettinstitute.nebra ska.edu/-/media/beci/docs/provider-survey-2-080420-final.pdf

DeLeeuw, E. D., Hox, J. J., \& Huisman, M. (2003). Prevention and treatment of item nonresponse. Journal of Official Statistics, 19, 153-176.

Dias, M. J. A., Almodóvar, M., Atiles, J. T., Vargas, A. C., \& León, I. M. Z. (2020). Rising to the Challenge: innovative early childhood teachers adapt to the COVID-19 era. Childhood Education, 96(6), 38-45. https://doi.org/10.1080/00094056.2020.1846385

Dorn, E., Hancock, B., Sarakatsannis, J., \& Viruleg, E. (2020). COVID19 and student learning in the United States: The hurt could last a lifetime. McKinsey \& Company. Retrieved from https://webte st.childrensinstitute.net/sites/default/files/documents/COVID-19and-student-learning-in-the-United-States_FINAL.pdf

Dowsett, C. J., Huston, A. C., Imes, A. E., \& Gennetian, L. (2008). Structural and process features in three types of child care for children from high and low income families. Early Childhood Research Quarterly, 23(1), 69-93.

Duncan, G. J., \& Magnuson, K. (2013). Investing in preschool programs. Journal of Economic Perspectives, 27(2), 109-132.

Education Development Center. (2020). Resources for the COVID-19 crisis. Retrieved from https://www.edc.org/resou rces-covid-19-crisis

Escamilla, I. M., \& Meier, D. (2018). The promise of teacher inquiry and reflection: early childhood teachers as change agents. Studying Teacher Education, 14(1), 3-21. https://doi.org/10.1080/17425 964.2017.1408463

Fantuzzo, J. W., LeBoeuf, W. A., Brumley, B., Coe, K., McDermott, P. A., \& Rouse, H. (2019). What's behind being behind? Using 
integrated administrative data to enhance our understanding of how publicly monitored early risk experiences uniquely affect children's growth in reading achievement. Children and Youth Services Review, 96, 326-335. https://doi.org/10.1016/j.child youth.2018.11.021

Federal Communications Commission. (2018). Broadband Deployment Report. Retrieved from https://www.fcc.gov/reports-resea $\mathrm{rch} /$ reports/broadband-progress-reports/2018-broadband-deplo yment-report

Friedman-Krauss, A., Barnett, W. S., Garver, K., Hodges, K., Weisenfield, GG., \& Gardiner, B.A. (2020). Early childhood education: Three Pathways to Better Health. Preschool Policy Update. National Institute for Early Education Research. Retrieved from https://nieer.org/wp-content/uploads/2018/12/NIEER-PolicyUpdate_Health_2019.pdf

Goffin, S. (2013). Early childhood education for a new era: Leading for our profession. Teachers College Press.

Greszler, R. (2020). Labor policy for COVID-19 and beyond: recsommendations to get Americans back to work. Heritage Foundation Backgrounder, 3506, 1-17.

Hanno, E. C. Gonzalez, K. E., Gardner, M., Jones, S. M., Lesaux, N. K., Hofer, K., Checkoway, A., \& Goodson, B. (2020). Pandemic Meets Preschool:Impacts of the COVID-19 Outbreak on Early Education and Care in Massachusetts. Saul Zaentz Early Education Initiative, Harvard Graduate School of Education. Retrieved from: https://zaentz.gse.harvard.edu/wp-content/uploads/2020/08/ ELS@H-COVID-Report_-ECE-Providers_Final_2.pdf

Hill, C. E., Thompson, B. J., \& Williams, E. N. (1997). A guide to conducting consensual qualitative research. The Counseling Psychologist, 25(4), 517-572.

Hodges, C., Moore, S., Lockee, B., Trust, T., \& Bond, A. (2020). The difference between emergency remote teaching and online learning. Educause Review, 27, 1-12.

Hunzicker, J. (2011). Effective professional development for teachers: a checklist. Professional Development in Education, 37(2), 177-179. https://doi.org/10.1080/19415257.2010.523955

Jeffrey, Szeftel, Herman (2020). Supporting Head Start Employee Well-Being During the COVID-19 Pandemic. JAACP Connect. Vol 7 issue 4. Retrieved from https://els-jbs-prodedn.jbs.elsev ierhealth.com/pb/assets/raw/Health\%20Advance/journals/jaac/ connect7_4.pdf\#page $=17$

Kwon, K. A., Ford, T. G., Salvatore, A. L., Randall, K., Jeon, L., Malek-Lasater, A., \& Han, M. (2020). Neglected elements of a high-quality early childhood workforce: whole teacher well-being and working conditions. Early Childhood Education Journal. https://doi.org/10.1007/s10643-020-01124-7

Landry, S. H., Assel, M. A., Swank, P. R., \& Anthony, J. L. (2009). An experimental study evaluating a state funded pre-kindergarten program: bringing together subsidized childcare public school, and head start. Society for Research on Educational Effectiveness. https://doi.org/10.1007/s11145-010-9243-1

McCoach, D. B., Gable, R. K., \& Madura, J. P. (2013). Review of the steps for designing an instrument. Instrument development in the affective domain (pp. 277-284). Springer Publishing Company.

Messick, S. (1995). Standards of validity and the validity of standards in performance assessment. Educational Measurement: Issues and Practice, 14(4), 5-8.

Nikolopoulou, K., \& Gialamas, V. (2015). ICT and play in preschool: Early childhood teachers' beliefs and confidence. International
Journal of Early Years Education, 23(4), 409-425. https://doi. org/10.1080/09669760.2015.1078727

NAEYC. (2019). Professional standards and competencies for early childhood educators. Retrieved from https://www.naeyc.org/resou rces/position-statements/professional-standards-competencies

Pachter, L. M., Coll, C. G., Perez-Brena, N. J., Lopez, L. M., Halgunseth, L. C., Mistry, R. S., Stein, G. L., \& Carlo, G. (2020). Assessing the impact of COVID-19 on children and youth. Delaware Journal of Public Health, 6(2a), 40-41.

Peele, H., \& Riser-Kositsky, M. (2020). Map: Coronavirus and School Closures. Education Week. Retrieved from https://www.edweek. org/ew/section/multimedia/map-coronavirusand-school-closures. html

Reich, J., Buttimer, C. J., Fang, A., Hillaire, G., Hirsch, K., Larke, L. R., ... \& Slama, R. (2020). Remote learning guidance from state education agencies during the covid-19 pandemic: A first look. Retrieved from https://edarxiv.org/437e2

Russell, B. S., Hutchison, M., Tambling, R., Tomkunas, A. J., \& Horton, A. L. (2020). Initial challenges of caregiving during COVID19: Caregiver burden, mental health, and the parent-child relationship. Child Psychiatry \& Human Development, 51(5), 671-682. https://doi.org/10.1007/s10578-020-01037-x

Safi, F., Wenzel, T., \& Spalding, L. A. T. (2020). Remote learning community: supporting teacher educators during unprecedented times. Journal of Technology and Teacher Education, 28(2), 211-222.

Samuelsson, I. P., Wagner, J. T., \& Ødegaard, E. E. (2020). The coronavirus pandemic and lessons learned in Preschools in Norway, Sweden and the United States: OMEP policy forum. International Journal of Early Childhood, 52(2), 129-144.

Szente, J. (2020). Live virtual sessions with toddlers and preschoolers amid COVID-19: implications for early childhood teacher education. Journal of Technology and Teacher Education, 28(2), 373-380.

Willis, G. B., Meeting of the American Statistical Association, \& Interviewing, I. C. (1999). A "How to" Guide. Research Triangle Institute: ResearchTriangle Park, NC, USA. Retreived from: https:// www.hkr.se/contentassets/9ed7b1b3997e4bf4baa8d4eceed5cd87/ gordonwillis.pdf

Willis, G. B. (2004). Cognitive Interviewing: A tool for improving questionnaire design. Sage Publications.

Yip, T. (2020, September 9). Addressing Inequities During the COVID19 pandemic: How Education policy and schools can support historically and currently marginalized children and youth. Retrieved from https://www.srcd.org/research/addressing-inequities-educa tion-during-covid-19-pandemic-how-education-policy-and-schoo ls

Yoshikawa, H., Wuermli, A. J., Britto, P. R., Dreyer, B., Leckman, J. F., Lye, S. J., \& Stein, A. (2020). Effects of the global COVID-19 pandemic on early childhood development: short-and long-term risks and mitigating program and policy actions. The Journal of Pediatrics, 223, 188-193. https://doi.org/10.1016/j.jpeds.2020. 05.020

Publisher's Note Springer Nature remains neutral with regard to jurisdictional claims in published maps and institutional affiliations. 